\title{
Risk Factors Associated with Diarrhea Morbidity Among Children Younger than Five Years in the Atwima Nwabiagya District, Ghana: A Cross-Sectional Study
}

\author{
Leslie Danquah ${ }^{1,}$, Charlotte Monica Mensah ${ }^{1}$, Seth Agyemang ${ }^{1}$, Esi Awuah ${ }^{2}$ \\ ${ }^{1}$ Department of Geography \& Rural Development, CASS, KNUST, Kumasi, Ghana \\ ${ }^{2}$ Universtiy of Energy and Natural Resources (UENR), Sunyani, Ghana
}

Email address:

kwasileslie@yahoo.com (L. Danquah)

\section{To cite this article:}

Leslie Danquah, Charlotte Monica Mensah, Seth Agyemang, Esi Awuah. Risk Factors Associated with Diarrhea Morbidity Among Children Younger than Five Years in the Atwima Nwabiagya District, Ghana: A Cross-Sectional Study. Science Journal of Public Health.

Vol. 3, No. 3, 2015, pp. 344-352. doi: 10.11648/j.sjph.20150303.17

\begin{abstract}
This study was conducted in January 2013 to identify risk factors associated with diarrhea morbidity among children younger than 5 years in the Atwima Nwabiagya District, Ghana. A total of 378 households were drawn from four Atwima Nwabiagya District communities in the dry season using a systematic random sampling strategy. Quantitative data was collected from eligible households using interviewer-administered questionnaires and spot-checks. The relationships of socio-demographic, environmental, and behavioral factors with childhood diarrhea were assessed via logistic regression. The mother's age [adjusted odds ratio $(\mathrm{aOR})=3.52,95 \%$ confidence interval $(\mathrm{CI})=1.11-11.16$ ] and educational level $(\mathrm{aOR}=4.77$, $95 \% \mathrm{CI}=1.85-12.28)$ and frequent playing on the bare ground with soil by the index child $(\mathrm{aOR}=3.14,95 \% \mathrm{CI}=1.40-7.05)$ were significant risk factors of childhood diarrhea. Water storage outside of the dwelling was significantly associated with a lower risk of diarrhea $(\mathrm{aOR}=0.42,95 \% \mathrm{CI}=0.19-0.89)$. In the study communities, we recommend providing more education to mothers regarding environmentally-related disease transmission mechanisms, encouraging safe disposal of children's stools, discouraging children from playing with soil on bare floors, and promoting safe drinking water storage.
\end{abstract}

Keywords: Childhood Diarrhea, Risk Factors, Dry Season, Ghana

\section{Introduction}

Worldwide, diarrhea is the second leading cause of death among children younger than 5 years, with approximately 4 billion cases occurring each year in this age group [1]. More than 1.5 million children younger than 5 years die from diarrhea, representing $17 \%$ of all deaths in this age group [2]. In sub-Saharan Africa, one in every six children dies before the age of 5 years [3].

In Ghana an estimated 9 million episodes of diarrhea and approximately 84,000 diarrhea-related deaths among children younger than 5 years are recorded annually [4]. In 2009, diarrheal diseases ranked third among the top 10 causes of hospital admissions for children under 5 years in Ghana, with a proportional morbidity rate of $5.1 \%$ [5]. Also in 2009, diarrheal diseases ranked sixth among the top 10 causes of deaths in children under 5 years, with a proportional mortality rate of $2.6 \%$ [5]. In the Ashanti region of Ghana, diarrheal diseases ranked second after malaria among the top 10 causes of admissions to hospitals in 2008 and 2009 to mid-2010 [6]. Diarrhea was also ranked third among the top 10 outpatient morbidities in the Atwima Nwabiagya District in 2008, 2009, and $2011[7,8]$.

Varied risk factors can be associated with childhood diarrhea. The effects of excreta disposal practices on childhood diarrhea have been demonstrated in earlier studies by Traore et al. [9] and Mertens et al. [10]. Both hospital based studies found an association between where children's stools were disposed of and hospital admissions for childhood diarrhea. The association between the presence of animals in the domestic environment and diarrhoea has been reported by Knight et al. [11]. Also, the effects of mother's hygienic practice and knowledge on childhood diarrhoea have been studied by Alam et al. in 1989 [12] and Dikassa in 1993 [13]. Additionally, the relationship between household socio-economic characteristics and childhood diarrhea has been elucidated in various studies conducted across the globe $[14,15,16,17]$. However, to our knowledge, little attention 
has been paid to public health data regarding socio-demographic, environmental, and behavioral risk factors associated with diarrhea morbidity among children younger than 5 years in the Ashanti Region of Ghana. Additional gaps in literature indicate that much is unknown about diarrheal disease risk factors, particularly in the Atwima Nwabiagya District. This article aims to address this gap by reporting the results of a cross-sectional study of risk factors associated with childhood diarrhea. Knowledge of the risk factors of diarrheal disease has the potential of aiding public health planning and interventions targeted at improving water, sanitation and hygiene services in the Atwima Nwabiagya District. This study formed part of a larger longitudinal study of domestic water use and childhood diarrhoea in the study area.

\section{Methods}

\subsection{Study Design and Setting}

This cross-sectional study was conducted in the Atwima Nwabiagya District, the third most populated in the Ashanti Region of Ghana, during January and February, 2013 (dry season) [19]. The district is predominantly rural having $68 \%$ and $32 \%$ of households living in rural and urban communities respectively [19]. We purposively chose four communities whose outpatient morbidity data indicated an increasing trend in childhood diarrhea cases from 2008 to 2011 [8]. These were Abuakwa, Nkawie, Asuofua, and Barekese. Abuakwa and Nkawie were urban communities whereas Asuofua, and Barekese were peri-urban. Six research assistants were recruited from the study communities to receive a 1-week training course in questionnaire administration, interviewing techniques, techniques for conducting spot-checks, data management, and research ethics. Quantitative data were collected using interviewer-administered questionnaires and spot-checks. Research instruments were pretested in Koben, a community in the Atwima Nwabiagya District, Ghana.

\subsection{Sampling Procedures}

A convenience sample of 378 households with children aged 5 years or younger was chosen based on budget constraints. This sample represented $1.07 \%$ of the total number of households in the district [19]. It comprised of 175 households in Abuakwa, 67 in Nkawie, with 65 and 71 households in Asuofua and Barekese respectively. Each community sample size represented $4 \%$ of the total number of households in the respective communities [7]. In order to facilitate the enumeration of households, the four study communities were mapped through reconnaissance surveys and were divided into 10 sectors each using major road networks. We estimated the number of households for study in each sector by dividing the total community sample size by the 10 sectors [20].

At the enumeration stage, a house was randomly chosen within each sector to serve as the starting point. Beginning with the starting point, every other house within each sector was visited, and the first household in a house that satisfied the inclusion criteria was enrolled for the study. A household's eligibility was based on two criteria. First, the household should have had at least one child aged 5 years or younger. Second, the mother should have been 18 years or older. Upon agreeing to participate in the study the mother signed an informed consent form. The "index child," was randomly selected in households with more than one child younger than 5 years. The global positioning system (GPS) locations of the enumerated households were collected using GARMIN Dakota $^{\mathrm{TM}} 10$ GPS handsets (Garmin Corporation, Schaffhausen, Switzerland) to facilitate data collection. This procedure was repeated in each study community until the required sample size per community was reached. After enumeration, the informed consent forms were compiled, and eligible households were visited and studied.

\subsection{Survey Tools}

The data collection tools we employed were structured surveys and spot-checks. The structured surveys were developed in English and administered in 'Twi' by trained enumerators who were fluent in both languages. Questions which were asked in the structured surveys centered on socio-demographic background characteristics of the enumerated households, domestic water sources, water collection and storage, water use, waste disposal methods, domestic sanitation and hygiene aspects as well as the 24-h and 2-week diarrhea prevalence for index children. Regarding spot-checks, we were interested in domestic water storage practice and sanitation aspects. Specifically, enumerators checked for whether drinking water storage containers were kept above the floor, if containers had a narrow mouth, the presence of a lid/cover, whether the drinking water storage container was covered at the time of the visit. With respect to sanitary aspects, enumerators checked for the presence of any form of faecal matter outside of the dwelling, presence of animals on the compound, the household's use of a latrine and the hygienic state of the latrine.

\subsection{Data Analysis}

The hypothesized factors were placed into three main categories: socio-demographic, environmental, and behavioral, as shown in Tables 2, 3, and 4 respectively. Bivariate logistic regression was used to assess the relationship between childhood diarrhea and each hypothesized factor. Multivariate logistic regression was performed separately for each variable category in steps, and only factors with a p-value $\leq 0.30$ were retained in the model $[21,22,23]$. In the first step, all hypothesized socio-demographic factors were assessed together; those with a $p$-value $\leq 0.30$ were retained in model 1 . In the second step, all environmental factors were assessed together, and those with a $p$-value $\leq 0.30$ were retained in model 2 ; in the third step, all behavioral factors were assessed together, and those with a p-value $\leq 0.30$ were retained in model 3 . In the fourth model, all factors in models 1, 2, and 3 were assessed together (Table 
5). This "final model" was an estimation of the overall effect of all three models [18].

In order to facilitate the univariable regressions, and comparison with a study in Egypt which demonstrated that children whose mothers were aged 35 or older had lower risk of diarrhoea, the ages of mothers in our study were recoded into a binary outcome, ' $\leq 35$ years' and ' $>35$ years' [24]. Diarrhea was defined as having three or more loose stools or one bloody loose stool during a 24-h period [25]. Diarrheal episodes were considered to have commenced when preceded by seven consecutive days without diarrhea and to have ended when the child was free from diarrheal symptoms for at least $24 \mathrm{~h}$ [26]. All water and sanitation facilities were defined as improved or unimproved according to the definitions of the Joint Monitoring Programme of the World Health Organization (WHO) and United Nations Children's Fund (UNICEF) [27]. 'Optimal access to domestic water" was defined as having $>100 \mathrm{~L}$ of water per capita per day in a household. We were interested in the index child's play on the bare ground with soil outside the dwelling because it had been demonstrated in earlier studies as a potential pathway to faeco-oral transmission for children younger than five years $[28,29]$. Mothers were asked to indicate how often their children played with bare soil outside their dwelling and their answers were recoded into binary outcomes 'yes' for responses such as 'less often', 'often', 'very and 'no' for 'not allowed to playing on the bare ground with soil'. Children's stool disposal were defined as 'safe' and 'unsafe'based on the possible faecal contamination of the environment [30]. We defined safe refuse disposal methods as using garbage bins, composting, burying, and incineration, whereas unsafe methods included dumping in an open field and uncontrolled burning.

Measurements employed using Predictive Analytics SoftWare v. 16 (PASW®; SPSS, Inc., Chicago, IL, USA) included disease prevalence rates, odds ratios (ORs) with 95\% confidence intervals (95\% CIs), [31]. An association was deemed to exist between two variables if the p-value was $\leq 0.05$.

\subsection{Ethical Approval}

Ethical approval for this research was provided by the Committee on Human Research, Publications, and Ethics (CHRPE) of the Kwame Nkrumah University of Science and Technology, School of Medical Sciences (CHRPE/AP/187/12). Additional approval was provided by the Atwima Nwabiagya District Assembly and Atwima Nwabiagya District Health Directorate.

\section{Results}

\subsection{Household Characteristics}

The mothers' mean age was 31 years, whereas that of their spouses was 38 years. Regarding marital status, a majority $(327,87 \%)$ of the mothers were married. A higher percentage $(10 \%)$ of mothers than fathers $(5 \%)$ had completed senior high school (Grade 12) education. While, 151 (40\%) mothers were predominantly engaged in trading and 120 (32\%) were self-employed, their spouses were predominantly self-employed $(157,43 \%)$ or drivers $(81,22 \%)$.

Approximately $84 \%$ of the 376 households lived in one-room apartments; 250 (66.5\%), 109 (29\%), and 17 (4.5\%) households had 1,2 , or 3 or more children younger than 5 years of age, respectively. Of the total number of households who had access to latrines in their homes $(n=113), 37(32.7 \%)$ owned the latrines, whereas $76(67.3 \%)$ indicated that the latrines were shared with their neighbors. Overall, improved sanitation coverage was poor because only $37(10 \%)$ of the study households used improved sanitation facilities, whereas $341(90 \%)$ used unimproved sanitation facilities. Regarding water, 355 (94\%) of households reported the use of improved sources of domestic water; however, the piped water supply coverage was low among the study households (42, 11.1\%).

\subsection{Factors Associated with Diarrhea}

The 24-h and 2-week diarrhea prevalence rates were 3.4\% and $11.4 \%$, respectively (Table 1 ).The respondent's age, mother's education level, storage of water on the compound, and frequent playing on the ground were all statistically significantly associated with childhood diarrhea. Children who lived in households in which the respondent was 35 years or younger were three times more likely to suffer diarrhea than children whose mothers were older than 35 years. The risk of childhood diarrhea was four times higher [adjusted odds ratio $(\mathrm{aOR})=4.77,95 \%$ confidence interval $(\mathrm{CI})$ 1.85-12.28)] among children whose mothers had completed SHS or higher, compared with children whose mothers had not completed SHS. Additionally, children who lived in households where domestic water was regularly stored on the compound had a lower risk of diarrhea $(\mathrm{aOR}=0.42,95 \%$ CI $0.19-0.89$ ) relative to children who lived in households where domestic water was regularly stored elsewhere. Children who often/regularly played on the ground were three times more likely to suffer childhood diarrhea in the multivariate analysis $(\mathrm{aOR}=3.14,95 \%$ CI 1.40-7.05).

Table 1. Household socio-demographic, water, and sanitation characteristics.

\begin{tabular}{lll}
\hline Socio-demographic characteristics & $\mathbf{N}=\mathbf{3 7 8}$ & \% \\
\hline Sites & & 175 \\
Abuakwa & 67 & 46 \\
Nkawie & 65 & 17 \\
Asuofua & 71 & 19 \\
Barekese & 31 years \\
Mean age of mother of index child $(\mathrm{n}=376)$ & & \\
\hline
\end{tabular}




\begin{tabular}{|c|c|c|}
\hline Socio-demographic characteristics & $\mathrm{N}=\mathbf{3 7 8}$ & $\%$ \\
\hline Mean age of father of index child $(n=337)$ & 38 years & \\
\hline Mothers' age range & $17-56$ years & \\
\hline Mean household size $(\mathrm{n}=376)$ & 5 & \\
\hline \multicolumn{3}{|l|}{ Mother completed SHS or higher $(\mathrm{n}=377)$} \\
\hline Yes & 38 & 10 \\
\hline No & 339 & 90 \\
\hline \multicolumn{3}{|l|}{ Father completed SHS or higher $(\mathrm{n}=355)$} \\
\hline Yes & 18 & 5 \\
\hline No & 337 & 95 \\
\hline \multicolumn{3}{|l|}{ Occupation of father of index child $(\mathrm{n}=365)$} \\
\hline Self-employed & 156 & 43 \\
\hline Driver & 81 & 22 \\
\hline Civil servant/government employee & 35 & 9 \\
\hline Farmer & 32 & 9 \\
\hline Trader & 29 & 8 \\
\hline Others & 32 & 9 \\
\hline \multicolumn{3}{|l|}{ Occupation of mother of index child } \\
\hline Trader & 150 & 40 \\
\hline Self-employed & 120 & 32 \\
\hline Housewife & 42 & 11 \\
\hline Unemployed & 31 & 8 \\
\hline Farmer & 20 & 5 \\
\hline Sales woman/service worker & 9 & 2 \\
\hline Others & 6 & 2 \\
\hline \multicolumn{3}{|l|}{ Marital status } \\
\hline Married & 327 & 87 \\
\hline Living with partner & 20 & 5 \\
\hline Single & 13 & 3 \\
\hline Divorced/separated & 9 & 2 \\
\hline Widowed & 9 & 2 \\
\hline \multicolumn{3}{|l|}{ Number of rooms } \\
\hline 1 & 315 & 83 \\
\hline 2 & 51 & 13 \\
\hline 3 & 10 & 3 \\
\hline More than 3 & 2 & 1 \\
\hline \multicolumn{3}{|c|}{ Number of children younger than 5 years in household $(n=376)$} \\
\hline 1 & 250 & 66 \\
\hline 2 & 109 & 29 \\
\hline 3 & 7 & 2 \\
\hline More than 3 & 10 & 3 \\
\hline \multicolumn{3}{|l|}{ Water source type } \\
\hline Improved & 357 & 94 \\
\hline Unimproved & 21 & 6 \\
\hline \multicolumn{3}{|l|}{ Latrine ownership } \\
\hline Privately owned & 37 & 10 \\
\hline Shared & 341 & 90 \\
\hline \multicolumn{3}{|l|}{ Sanitation type } \\
\hline Improved & 37 & 10 \\
\hline Unimproved & 341 & 90 \\
\hline \multicolumn{3}{|l|}{ Diarrhea prevalence rate } \\
\hline $24 \mathrm{~h}$ & $13 / 378$ & 3.4 \\
\hline 2 weeks & $43 / 378$ & 11.4 \\
\hline
\end{tabular}

Source: Author's field survey, 2013; n, number of valid observations; N, total sample size; SHS, senior high school. 

Atwima Nwabiagya District, Ghana: A Cross-Sectional Study

Table 2. Bivariate logistic regression of socio-demographic factors associated with childhood diarrhea.

\begin{tabular}{|c|c|c|c|}
\hline \multirow{2}{*}{ Socio-demographic factors } & \multicolumn{2}{|c|}{ Diarrhea (2 weeks) } & \multirow{2}{*}{ Crude OR (95\% CI) } \\
\hline & Yes $(\%)$ & No $(\%)$ & \\
\hline \multicolumn{4}{|l|}{ HH numbers $\geq 5$} \\
\hline Yes & $22(12)$ & $164(88)$ & $1.08(0.57-2.03)$ \\
\hline No & $21(11)$ & $169(89)$ & 1 \\
\hline \multicolumn{4}{|l|}{ Respondents age is $\leq 35$ years } \\
\hline Yes & $38(13)$ & $254(87)$ & $2.99(1.03-8.64)$ \\
\hline No & $4(5)$ & $80(95)$ & 1 \\
\hline \multicolumn{4}{|c|}{ Mother completed SHS or higher } \\
\hline Yes & $9(24)$ & $29(76)$ & $2.78(1.21-6.36)$ \\
\hline No & $34(10)$ & $305(90)$ & 1 \\
\hline \multicolumn{4}{|c|}{ Spouse completed SHS or higher } \\
\hline Yes & $3(17)$ & $15(83)$ & $1.48(0.41-5.35)$ \\
\hline No & $40(12)$ & $297(88)$ & 1 \\
\hline \multicolumn{4}{|l|}{ Respondent is a house wife } \\
\hline Yes & $6(8)$ & $67(92)$ & $0.64(0.26-1.60)$ \\
\hline No & $37(12)$ & $268(88)$ & 1 \\
\hline \multicolumn{4}{|l|}{ Spouse is self-employed } \\
\hline Yes & $23(11)$ & $194(89)$ & $0.75(0.40-1.43)$ \\
\hline No & $20(13)$ & $128(87)$ & 1 \\
\hline \multicolumn{4}{|l|}{ HH residential location } \\
\hline Urban & $29(12)$ & $213(88)$ & 1 \\
\hline Peri-urban & $14(10)$ & $122(90)$ & $0.84(0.42-1.65)$ \\
\hline \multicolumn{4}{|c|}{ Number of under 5 children in $\mathrm{HH}$} \\
\hline One & $28(11)$ & $222(89)$ & $0.93(0.47-1.81)$ \\
\hline Two or more & $15(12)$ & $111(88)$ & 1 \\
\hline
\end{tabular}

Source: Author's field survey, 2013; CI, confidence interval; HH, household; OR, odds ratio; SHS, senior high school.

Table 3. Bivariate logistic regression of environmental factors associated with childhood diarrhea.

\begin{tabular}{|c|c|c|c|}
\hline \multirow{2}{*}{ Environmental factors } & \multicolumn{2}{|c|}{ Diarrhea (2 weeks) } & \multirow{2}{*}{ Crude OR (95\% CI) } \\
\hline & Yes $(\%)$ & No $(\%)$ & \\
\hline \multicolumn{4}{|l|}{ Latrine ownership } \\
\hline Private & $4(11)$ & $33(89)$ & $0.90(0.25-3.14)$ \\
\hline Shared & $9(12)$ & $67(88)$ & 1 \\
\hline \multicolumn{4}{|l|}{ HH sanitation } \\
\hline Improved & $4(11)$ & $33(89)$ & $0.93(0.31-2.79)$ \\
\hline Unimproved & $39(11)$ & $302(89)$ & 1 \\
\hline \multicolumn{4}{|l|}{ Latrine door } \\
\hline Available & $11(14)$ & $68(86)$ & $1.13(0.12-10.11)$ \\
\hline Not available & $1(12)$ & $7(88)$ & 1 \\
\hline \multicolumn{4}{|l|}{ Latrine lid } \\
\hline Available & $7(19)$ & $30(81)$ & $2.14(0.62-7.39)$ \\
\hline Not available & $5(10)$ & $46(90)$ & 1 \\
\hline \multicolumn{4}{|l|}{ Feces seen on compound } \\
\hline Yes & $20(12)$ & $148(88)$ & $1.09(0.57-2.06)$ \\
\hline No & $23(15)$ & $186(85)$ & 1 \\
\hline \multicolumn{4}{|l|}{ Refuse disposal } \\
\hline Safe & $9(7)$ & $124(93)$ & 1 \\
\hline Unsafe & $34(15)$ & $194(85)$ & $2.41(1.12-5.20)$ \\
\hline
\end{tabular}

Source: Author's field survey, 2013; HH, household; CI, confidence interval; OR, odds ratio. 
Table 4. Bivariate logistic regression of behavioral factors associated with childhood diarrhea.

\begin{tabular}{|c|c|c|c|}
\hline \multirow{2}{*}{ Behavioral factors } & \multicolumn{2}{|c|}{ Diarrhea ( 2 weeks) } & \multirow{2}{*}{ Crude OR $(95 \%$ CI $)$} \\
\hline & Yes (\%) & No (\%) & \\
\hline \multicolumn{4}{|c|}{ HH domestic water source } \\
\hline Improved & $40(11)$ & $317(89)$ & 1 \\
\hline Unimproved & $3(14)$ & $18(86)$ & $1.32(0.37-4.68)$ \\
\hline \multicolumn{4}{|c|}{$\mathrm{HH}$ drinking water source } \\
\hline Improved & $36(13)$ & $249(87)$ & 1 \\
\hline Unimproved & $7(8)$ & $83(92)$ & $0.58(0.25-1.36)$ \\
\hline \multicolumn{4}{|c|}{ HH has "optimal access" to domestic water } \\
\hline Yes & $2(18)$ & $9(82)$ & $1.68(0.35-8.07)$ \\
\hline No & $41(12)$ & $311(88)$ & 1 \\
\hline \multicolumn{4}{|c|}{ Drinking water is stored in a large drum outside the dwelling } \\
\hline Yes & $13(7)$ & $174(93)$ & $0.38(0.19-0.77)$ \\
\hline No & $28(16)$ & $146(84)$ & 1 \\
\hline \multicolumn{4}{|c|}{ Method of obtaining water } \\
\hline Pouring & $1(6)$ & $16(94)$ & $0.56(0.07-4.40)$ \\
\hline Dipping with cup & $34(10)$ & $308(90)$ & \\
\hline \multicolumn{4}{|c|}{ Storage vessel covered } \\
\hline Yes & $33(11)$ & $255(89)$ & $1.48(0.59-3.69)$ \\
\hline No & $6(8)$ & $69(92)$ & 1 \\
\hline \multicolumn{4}{|c|}{ Children's stool disposal } \\
\hline Safe & $35(17)$ & $253(83)$ & $0.89(0.39-2.05)$ \\
\hline Unsafe & $8(13)$ & $52(87)$ & 1 \\
\hline \multicolumn{4}{|c|}{ Child often plays on the bare ground with soil outside the dwelling } \\
\hline Yes & $33(17)$ & $159(83)$ & $3.32(1.58-6.96)$ \\
\hline No & $10(6)$ & $160(94)$ & 1 \\
\hline \multicolumn{4}{|c|}{ Mother washes hands with soap and water often after cleaning bottom of child } \\
\hline Yes & $22(10)$ & $190(90)$ & $0.79(0.42-1.51)$ \\
\hline No & $21(13)$ & $145(87)$ & 1 \\
\hline
\end{tabular}

Source: Author's field survey, 2013; CI, confidence interval; HH, household; OR, odds ratio.

Table 5. Multivariate logistic regression analysis of the socio-demographic, environmental, and behavioral factors associated with childhood diarrhea.

\begin{tabular}{|c|c|c|c|c|}
\hline Risk factors & Model 1 aOR (95\% CI) & Model 2 aOR (95\% CI) & Model 3 aOR (95\% CI) & Final model aOR $(95 \% \mathrm{CI})$ \\
\hline \multicolumn{5}{|c|}{ Respondents age is $\leq 35$ years } \\
\hline Yes & $3.46(1.11-10.76)$ & & & $3.52(1.11-11.16)$ \\
\hline No & 1 & & & 1 \\
\hline \multicolumn{5}{|c|}{ Mother completed SHS or higher } \\
\hline Yes & $3.47(1.33-9.07)$ & & & $4.77(1.85-12.28)$ \\
\hline No & 1 & & & 1 \\
\hline \multicolumn{5}{|c|}{ Latrine ownership } \\
\hline Private & & $4.69(0.48-45.95)$ & & \\
\hline Shared & & 1 & & \\
\hline \multicolumn{5}{|c|}{$\begin{array}{l}\text { HH has "optimal access" to } \\
\text { domestic water }\end{array}$} \\
\hline Yes & & & $3.05(0.58-16.04)$ & $3.59(0.65-19.81)$ \\
\hline No & & & 1 & 1 \\
\hline \multicolumn{5}{|c|}{$\begin{array}{l}\text { Drinking water is stored in a large } \\
\text { drum outside the dwelling }\end{array}$} \\
\hline Yes & & & $0.42(0.18-0.96)$ & $0.42(0.19-0.89)$ \\
\hline No & & & 1 & 1 \\
\hline \multicolumn{5}{|c|}{$\begin{array}{l}\text { Child often plays on the bare } \\
\text { ground with soil outside the } \\
\text { dwelling }\end{array}$} \\
\hline Yes & & & $2.14(0.94-4.85)$ & $3.14(1.40-7.05)$ \\
\hline No & & & 1 & 1 \\
\hline
\end{tabular}

Source: Author's field survey, 2013; aOR, adjusted odds ratio; CI, confidence interval; HH, household.

A multivariate logistic regression was performed to identify the risk factors for childhood diarrhea in the dry season, and the results are shown in Table 5. In model 1, only the respondent's age $(\mathrm{aOR}=3.46,95 \%$ CI 1.11-10.76) and mother's completion of SHS or higher $(\mathrm{aOR}=3.47,95 \% \mathrm{CI}$
1.33-9.07) had p-values $\leq 0.30$ in the multivariate logistic regression analysis of socio-demographic variables. In model 2 , only private latrine ownership $(\mathrm{aOR}=4.69,95 \% \mathrm{CI}$ $0.18-45.95$ ) had a $p$-value $\leq 0.30$ during the multivariate logistic regression analysis of environmental variables. In 
model 3, optimal access to domestic water $(\mathrm{aOR}=3.05,95 \%$ CI 0.58-16.04), drinking water is stored in a large drum outside the dwelling ( $\mathrm{aOR}=0.42,95 \%$ CI $0.18-0.96$ ), and frequent playing on the ground $(\mathrm{aOR}=2.14,95 \% \mathrm{CI}$ $0.94-4.85$ ) had $p$-values $\leq 0.30$ in the multivariate logistic regression analysis of behavioral variables.

\section{Discussion}

A bivariate analysis of socio-demographic factors revealed that the mother's age and completion of SHS were statistically significantly associated with childhood diarrhea (Table 2). The risk of childhood diarrhea was higher among children with mothers aged 35 years or younger $(\mathrm{OR}=2.99,95 \% \mathrm{CI}$ 1.03-8.64). This result suggests that younger mothers might be less experienced or have less knowledge about disease transmission mechanisms in the domestic environment relative to their older counterparts. Also, the risk of diarrhea was higher among children whose mothers had completed SHS (OR $=2.78,95 \%$ CI $1.21-6.36)$. It is worth noting that this finding is relatively counter-intuitive compared to other studies. For example, a study in Guinea-Bissau found a $25 \%$ reduction in diarrheal disease among children whose mothers had more than 7 years of education [32]. No statistically significant relationship was found between childhood diarrhea and household size (OR $=1.08,95 \%$ CI $0.57-2.03)$, spouse's completion of SHS or higher $(\mathrm{OR}=1.48,95 \% \mathrm{CI} 0.41-5.35)$, housewife status of the respondent $(\mathrm{OR}=0.64,95 \% \mathrm{CI}$ $0.26-1.60)$, self-employed spouse $(\mathrm{OR}=0.75,95 \% \mathrm{CI}$ $0.40-1.43)$, residential location $(\mathrm{OR}=0.84,95 \% \mathrm{CI}$ $0.42-1.65)$, or the number of children younger than 5 years in the household $(\mathrm{OR}=0.93,95 \%$ CI $0.47-1.81)$. However, an earlier study in Egypt showed that regarding household size, children in larger families were more likely to have diarrhea, partly because children received less attention and had poorer hygiene due to the large family size [24].

Regarding the bivariate analysis of environmental factors (Table 3), latrine lid availability and unsafe refuse disposal had $\mathrm{p}$-values $\leq 0.30$. Only unsafe refuse disposal showed a statistically significant relationship with childhood diarrhea. Children who lived in households where unsafe refuse disposal was practiced were two times more likely to suffer diarrhea $(\mathrm{OR}=2.41,95 \%$ CI $1.12-5.20)$ relative to children who lived in households that practiced safe refuse disposal.. This result is consistent with studies conducted in Ethiopia [18] which found that improper refuse disposal was associated with a higher risk of childhood diarrhea $(\mathrm{OR}=2.22,95 \% \mathrm{CI}$ 1.20-4.03), and Reggassa et al. [33] who found that compared with households that disposed refuse in open areas, children living in households that used a pit or garbage bin and burned garbage had a lower risk of diarrhea $(\mathrm{OR}=0.31,95 \% \mathrm{CI}$ $0.11-0.87$ ).

In the bivariate analysis of behavioral factors (Table 3), two factors were statistically significantly associated with childhood diarrhea: water storage on the compound of the dwelling and frequent playing on the ground (Table 4). Children who lived in households where water was stored on the compound had a lower risk of diarrhea relative to children who lived in households where water was stored in the dwelling. This result suggests that stored water contamination occurs in the dwelling, possibly because of crowded conditions, and implies that storage on the compound is safer. The risk of diarrhea was three times higher among children who often/regularly played on the bare floor with soil (OR = $3.32,95 \%$ CI 1.58-6.96) relative to those who did not. Fecal matter might be deposited on the bare floor by means such as soiled human feet, footwear, animal feet, flies, or open defecation. Children might still receive infectious doses of pathogens because they are considered too young to wash their own hands or to take adequate precautions while playing on the bare floor with soil and therefore cannot stop the transfer of pathogens between their hands and mouths [34].

No statistically significant association was found between childhood diarrhea and domestic water sources $(\mathrm{OR}=1.32$, 95\% CI 0.37-4.68), drinking water sources $(\mathrm{OR}=2.99,95 \%$ CI 1.03-8.64), optimal access to water $(\mathrm{OR}=1.68,95 \%$ CI 1 0.35-8.07), the method of obtaining water from storage vessels $(\mathrm{OR}=0.56,95 \% \mathrm{CI} 0.07-4.40)$, covering of water storage vessels $(\mathrm{OR}=1.48,95 \%$ CI $0.59-3.69)$, or mothers washing their hands with water and soap after cleaning their children's bottoms ( $\mathrm{OR}=0.79,95 \%$ CI $0.42-1.51)$. An earlier study in Burkina-Faso found that children whose mothers regularly disposed of feces in the latrine had an approximate $40 \%$ reduction in the diarrhea rate [9]. However, in both the bivariate and multivariate analyses, no statistically significant association was found between children's stool disposal and childhood diarrhea $(\mathrm{OR}=0.89$, 95\% CI 0.39-2.05). Safe stool disposal methods included the use of latrines, pouring/rinsing into latrines, and burying, whereas unsafe methods included putting/rinsing into a drain and leaving in the open. The results of this study suggest that efforts to mitigate childhood diarrhea should target socio-demographic and behavioral factors, which were relatively significant determinants of childhood diarrhea. However, the identification of low improved sanitation facility coverage $(10 \%)$ and evidence of fecal matter on the compounds of 168 (44.6\%) of households (Table 3), indicates that stool disposal also merits attention.

Our study has some limitations. This was a cross-sectional study, and therefore, causal relationships of socio-demographic, environmental, and behavioral factors with childhood diarrhea could not be established. Also, the study was limited to the dry season, and the children's ages, child feeding practices, nipple hygiene, and mothers' previous histories of diarrhea were not included in the analysis. The effect of 'often playing on the bare ground with soil outside the dwelling' could have been confounded by the ages of the children. Our study may also be subject to recall bias on the part of the mother due to the reliance on two (2) week recall. Enumerators spent an average of one hour during data collection in each household and they could only conduct the spot-check based on the sanitation, hygiene and environmental conditions in the household for that period. We believe that future research could benefit more from an 
extended period of household observation in a day as well as repeated household visits.

\section{Conclusions}

In this cross-sectional study, we identified the mother's age, and education and frequent playing on the bare ground with soil as significant risk factors associated with diarrhea during the dry season in children younger than 5 years, whereas water storage outside the dwelling was significantly associated with a lower risk of diarrhea. In light of these findings, we suggest that educating mothers about the mechanisms of environmentally related disease transmission, promoting the safe disposal of children's stools, encouraging safe water storage, and suggesting that mothers ensure that their children do not play on the bare ground with soil are potential measures through which to address childhood diarrhea in our study communities. In addition, future research into domestic drinking water quality, child feeding practices, nipple hygiene, and children's play environments could shed more light on other risk factors.

\section{Abbreviations}

GPS, global positioning system; SHS, senior high school; UNICEF, United Nations Children's Fund; WHO, World Health Organization

\section{Acknowledgements}

We are grateful to the Atwima Nwabiagya District Assembly and the District health directorate for their assistance at the data collection stage of the study.

\section{References}

[1] UNICEF/WHO, 2009. Why are children still dying and what can be done? World Health Organization, Geneva.

[2] UNICEF, 2010. Facts for life, fourth edition. United Nations Children's Fund, New York.

[3] UNICEF, 2007. State of the world's children 2008: Child survival. United Nations Children's Fund, New York.

[4] Scott, B., Curtis, V., Rabie, T., Garbrah-Aidoo, N., 2007. Health in our hands, but not in our heads: Understanding hygiene motivation in Ghana. Health Policy Plan. 22, 225-233.

[5] Ghana Health Service (GHS), 2009. The health sector in Ghana: Facts and figures 2009. Ghana Health Service, Accra.

[6] Ghana Health Service (GHS), 2010. Ashanti regional health directorate half year report 2010. Ghana Health Service, Kumasi.

[7] ANDA, 2011. Atwima Nwabiagya District Profile. Atwima Nwabiagya District Assembly, Nkawie.

[8] Ghana Health Service (GHS), 2011. Health Information Unit data set. Ghana Health Service, Kumasi.
[9] Traore, E., Cousens, S., Curtis, V., Mertens, T., Tall, F., Traore, A., Kanki, B., Diallo, I., Rochereau, A., Chiron, J.P., Megraud, F., 1994. Child defecation behavior, stool disposal practices and childhood diarrhoea in Burkina Faso: results from a case-control study. J. Epidemiol Comm. Health. 48, 270-275.

[10] Mertens, T.E., Jaffar, S., Fernando, M.A., Cousens, S.N., Feachem, R.G., 1992. Excreta disposal behavior and latrine ownership in relation to the risk of childhood diarrhoea in Sri Lanka. Int. J. Epidemiol. 21, 1157-1164

[11] Knight, S.M., Toodayan, W., Caique, W.C., Kyi, W., Barnes, A Desmarchelier, P., 1992. Risk factors for the transmission of diarrhoea in children: A case-control study in rural Malaysia. Int. J. Epidemiol. 21, 812-818.

[12] Alam, N., Wojtyniak, B., Henry, F.J., Rahaman, M.M., Wojtyniak, B., 1989. Mothers' personal and domestic hygiene and diarrhoea incidence in young children in rural Bangladesh. Int. J. Epidemiol. 18, 242-247.

[13] Dikassa, L., Mock, N., Magnani, R., Rice, J., Abdoh, A., Mercer, D., Bertrand, W., 1993. Maternal behavioural risk factors for severe childhood diarrhoeal disease in Kinshasa, Zaire. Int. J. Epidemiol. 22, 327-333.

[14] Alam, N., 1995. Birth spacing and infant and early childhood mortality in a high fertility area of Bangladesh; age-dependent and interactive effects. J. Biosoc. Sci. 27, 393-404.

[15] Katema, L., Lulseged, S., 1997. Persistent diarrhoea: Socio-demographic and clinical profile of 264 children seen at referral hospitals in Addis Ababa. Ethiop. Med. J. 35, 616-618.

[16] Timaeus, I.M., Lush, L., 1995. Intra-urban differentials in child health. Health Transit. Rev. 5, 163-190.

[17] Ferrer, S.R., Strina, A., Jesus, S.R., Ribeiro, S.R., Cairncross, S., Rodrigues, L.C., Barreto, M.L., 2008. A hierarchical model for studying risk factors for childhood diarrhoea: a case-control study in a middle income country. Int. J. Epidemiol. 37, $805-815$.

[18] Mengistie, B., Berhane, Y., Worku, A., 2013. Prevalence of diarrhea and associated factors among children under-five years of age in Eastern Ethiopia. A cross-sectional study. Open J. Prev. Med. 3, 446-453.

[19] GSS, 2014. 2010 Population and housing census. District Analytical Report, Atwima Nwabiagya District. Ghana Statistical Service, Accra.

[20] Danquah, L., Awuah, E., Mensah., C. M., and Agyemang, S. 2014. Sanitation and Hygiene Practices in Relation to Childhood Diarrhoea Prevalence: The Case of Households with Children under-Five Years in Ghana. Sc. J. Pub. Health. 2, 119-125. doi: 10.11648/j.sjph.20140202.21

[21] Dessalegn, M., Kumie, A., Tefera, W., 2011. Predictors of under-five childhood diarrhoea, Mecha District, West Gojam, Ethiopia. Ethiop. J. Health Dev. 25,192-200.

[22] Mulugeta, T., 2003. Socio-economic, environmental and behavioural factors associated with the occurrence of diarrheal disease among under-five children in Meskanena Mareko Woreda, Southern Ethiopia. Unpublished MPH thesis. Addis Ababa University, Ethiopia.

[23] Victora, C.G., Huttly, S.R., Fuchs, S.C., Olinto, M.T.A., 1997. The role of conceptual frameworks in epidemiological analysis: A hierarchical approach. Int. J. Epidemiol. 26, 224-227. 
[24] El-Gilany, A.H., Hammad, S., 2005. Epidemiology of diarrhoeal diseases among children under age 5 years in Dakahlia, Egypt. East Mediterr. Health J. 2, 762-775.

[25] Jensen, P.K., Jayasinghe, G., van der Hoek, W., Cairncross, S., Dalsgaard, A., 2004. Is there an association between bacteriological drinking water quality and childhood diarrhoea in developing countries? Trop. Med. Int. Health. 9, 1210-1215.

[26] Paniagua, M., Espinoza, F., Ringman, M., Reizenstein, E., Svennerholm, A.M., Hallander, H., 1997. Analysis and incidence of infection with Enterotoxigenic Escherichia coli in a prospective cohort study of infant diarrhea in Nicaragua. J. Clin. Microbiol. 35, 1404-1410.

[27] WHO/UNICEF, 2013. Progress on sanitation and drinking water: 2013 update. Geneva: World Health Organization.

[28] Ngure, F.M., Humphrey, J. H., Mbuya, M. N. N., Majo, F., Mutasa, K., Govha, M., Mazarura, E., Chasekwa, B., Prendergast, A. J., Curtis, V., Boor, K. J., and Stoltzfus, R. J., 2013. Formative research on hygiene behaviors and geophagy among infants and young children and implications of exposure to fecal bacteria. Am. J. Pub. Trop. Med. and Hygiene, 89, 709 716

[29] Marquis, G.S., Ventura, G., Gilman, R.H., Porras, E., Miranda, E., Carbajal, L., Pentafiel, M., 1990. Fecal contamination of shanty town toddlers in households with non-corralled poultry, Lima, Peru. Am. J. Pub. Health. 80, 146-149.
[30] Majorin, F., Freeman M.C., Barnard, S., Routray, P., Boisson, S., Clasen, T., 2014. Child Feces Disposal Practices in Rural Orissa: A Cross Sectional Study. PLoSONE 9, e89551. doi:10.1371/journal.pone.0089551

[31] Cifuentes, E., Suarez, L., Solano, M., Santos, R., 2002. Diarrhoeal diseases in children from a water reclamation site in Mexico City. Environ. Health Perspect. 110, A619-A624.

[32] Molbak, K., Jensen, H., Ingholt, L., Aaby, P., 1997. Risk factors for diarrheal disease incidence in Early Childhood: A Community Cohort Study from Guinea-Bissau. Am. J. Epidemiol. 146, 273-282.

[33] Regassa, G., Birke, W., Deboch, B., Belachew, T., 2008. Environmental determinants of diarrhoea among under-five children. Ethiop. J. Health Sci. 18, 39-45.

[34] Luby, S.P., Agboatwalla, M., Painter, J., 2004. Effect of intensive hand washing promotion on childhood diarrhoea in high-risk communities in Pakinstan: a randomized controlled trial. JAMA. 291, 2547-2554. 